\title{
FALAR DOS OUTROS, SABER DOS OUTROS
}

María José Guzmán ${ }^{1}$

\section{Resumo}

$\mathrm{O}$ artigo apresenta a questão do saber na contemporaneidade segundo três autores: Clastres, Foucault e Rancière. Desde perspectivas bem diferentes, mas assumindo o compromisso de pensar o político de maneira radical e evitando o modelo do poder centralizado, todos eles discutem o estatuto do saber, sua construção e sua transmissão e obrigam a repensar diferentes aspectos dessa problemática: a alteridade, a diferença, a produção dos outros através do saber, a necessidade política da explicação, etc.

Palavras-chave: Educação. Política. Sujeição. Hierarquia. Alteridade.

\section{Resumen}

El artículo presenta la cuestión del saber en la contemporaneidad según tres autores: Clastres, Foucault y Rancière. Desde perspectivas bien distintas, pero asumiendo el compromiso de pensar lo político de manera radical y evitando el modelo del poder centralizado, todos ellos discuten el estatuto del saber, su construcción y su transmisión y obligan a repensar diferentes aspectos de esa problemática: la alteridad, la diferencia, la producción de los otros a través del saber, la necesidad política de la explicación, etc.

Palabras clave: Educación. Política. Sujeción. Jerarquía. Alteridad.

\section{Notas iniciais}

Em uma análise sobre o conhecimento na contemporaneidade, Franklin Leopoldo e Silva (1997) nos relembra que entre as ambições da ciência moderna se contava a de integrar a totalidade do saber com - nada menos que - a consecução da felicidade humana. Silva identifica a Descartes e a Locke como os pais de uma nova forma de conhecimento que se destaca por sua vontade de unificação do saber. Esse saber que aspirava a ser puramente racional concretizouse sob o modelo da matemática, que trabalha com certezas puramente intelectuais e com objetos abstratos. Uma vontade de unidade estendeu esse modelo - que prometia um máximo de eficácia - à totalidade das ciências.

Ainda que seja difícil negar o sucesso da ciência moderna no sentido de promover o progresso do saber e da técnica, garantindo um domínio da natureza

\footnotetext{
1 Bolsista de pós-doutorado (CAPES), Faculdade de Educação, UESB. Correio eletrônico:
} mmjj10@yahoo.com.

GUZMÁN, María José. Falar dos outros, saber dos outros. Revista Sul-Americana de Filosofia e Educação. Número 25: nov/2015 - abril/2016, p. 172-191. 
sem precedentes, foi se fazendo evidente, com o tempo, que o progresso não necessariamente se traduz em felicidade. Benjamin, dentre outros, já o denunciava; Adorno e Horkheimer, na esteira benjaminiana, o colocam nos seguintes termos: existe uma dialética histórica entre progresso e regressão: a razão moderna avança ao mesmo tempo em que cria sua própria barbárie ética, política, epistemológica ${ }^{2}$. A crítica do pensamento unificante, totalitário, globalizante, etc. assume muitas formas na filosofia do século passado. Michel Foucault, de quem nos ocuparemos neste artigo, também afirma que "a relação entre a racionalização e os excessos do poder político é evidente" (1995, p. 233), concordando assim com o diagnóstico frankfurtiano; Foucault acrescenta, contudo, que ele prefere falar de racionalidades específicas e não da racionalidade como uma coisa só. Voltaremos sobre este assunto.

Como o expressa Silva (1997) a barbárie que habita o conhecimento racional ameaça com a "dissolução da realidade no ato de sua transformação em objeto de conhecimento". Ante essa insuficiência do conhecimento, amarrado às exigências da unificação para abordar os problemas da subjetividade, o desafio é pensar em sujeitos enquanto eles encarnam formas diversas - muito diversas - de estar no mundo, o que implica formas diversas de saber e de relações de poder. Reconhecer essa diversidade significa reconhecer também os conflitos e tensões entre sujeitos e grupos. Destacamos dois pressupostos que se derrubam junto com a idealização da unidade: por um lado, o da ciência como um todo coeso, por outro, o da potência de unificação, que interpreta o que não se ajusta à totalidade como estando em vias de se ajustar. No segundo caso a operação unificadora funciona prometendo que tudo aquilo que não se sujeita está a caminho de se integrar ${ }^{3}$. Por trás dessa promessa e oculto por ela, subsiste um paradoxo entre o que as práticas e saberes modernos prometem e o que eles produzem. É importante dizer que para os autores que aqui trataremos esse paradoxo faz parte

\footnotetext{
2 Essa questão aparece insistentemente na obra benjaminiana, por exemplo nas suas célebres teses "Sobre o conceito da História" (1994) e é tema central na Dialética do Esclarecimento (ADORNO; HORKHEIMER, 1985)

${ }^{3}$ Nessa introdução, dada sua generalidade, utilizamos os conceitos de unificar e sujeitar de um modo um tanto vago, o importante para nós é a característica de negar ou tentar dominar o diverso. A seguir preferiremos falar em sujeitar.
} 
do conhecimento mesmo e não é um elemento externo que o próprio conhecimento poderia um dia eliminar.

Para muitos pensadores, a educação, enquanto problematização da transmissão dos saberes e tentativa de mudança das práticas, se inscreve no seio desse impasse, nesse paradoxo: em ocasiões promete autonomia e não raro produz obediência, quase sempre promete trabalho mais digno e produz apenas excesso de mão-de-obra, com frequência promete igualdade e reproduz desigualdade, promete liberdade e cria dívidas - econômicas, mas não apenas.

Os três autores que apresentaremos não ignoram os paradoxos $e$ contradições do saber aos quais temos nos referido. Eles pensam o político fora do modelo do poder centralizado e centralizador - isto é, unificado. Dentre eles, o mais difundido no campo da educação é Michel Foucault; lembraremos aqui algumas questões centrais do seu pensamento sobre o poder, o saber e sua transmissão: poder pastoral, disciplina, biopoder e governo de si. Antes de Foucault, apresentaremos o antropólogo político Pierre Clastres, cuja experiência mostra as possibilidades o os riscos de um saber sobre os outros que se constrói desconstruindo o próprio e desafia a pensar a alteridade fora do modelo da identidade. Essa alteridade faz ressoar nos textos clastrianos a pergunta sobre um paradoxo político contemporâneo que ele identifica com a fórmula de La Boétie: a servidão voluntária. Finalmente veremos que Jacques Rancière trata a questão da transmissão do saber denunciando uma contradição fundamental - a promessa de igualdade - que excede as relações educativas e desafia o pensamento pedagógico e político a considerar a figura do mestre desde novos pontos de vista. Essas três perspectivas provocam pelo menos uma boa parte das ideias vigentes sobre a prática de ensinar e de pensar.

\section{Pierre Clastres: Como falar sobre os outros? Por que falar sobre os outros?}

O antropólogo político francês Pierre Clastres publicou em $1974 A$ sociedade contra o Estado (2011), fruto de suas pesquisas de campo entre os índios da América do Sul. Nele apresenta sua crítica à distinção entre sociedades primitivas e sociedades civilizadas, definidas as primeiras pela falta de Estado e 
consideradas as segundas como pertencendo a um estágio mais avançado da história humana.

Descritas por via negativa pelos europeus que se depararam com elas, as formas de organização social das tribos indígenas estudadas por Clastres foram definidas como primitivas por carecerem de Estado, mas não apenas por isso: já os colonizadores as consideravam integramente pela falta: sociedades "sem fé, sem lei, sem rei" (CLASTRES, 2011, p. 138) - e não devemos esquecer que elas "carecem" também de escola!

O livro $A$ sociedade contra o Estado (CLASTRES, 2013) defende a tese de que, contudo, as chamadas sociedades primitivas não são sociedades que ainda não chegaram a se organizar a partir de um Estado, senão que elas evitam expressamente, através de suas regras, essa forma de organização e de exercício do poder: contra o Estado. Estas comunidades estabelecem normas que impedem que o poder se aglutine numa instância única que paira por cima (separada) do corpo social. Viveiros de Castro (2011, p. 318-9) o expressa em termos deleuzianos: não há nessa organização política uma instância de poder transcendente, o poder circula na imanência. Ele enfatiza: "a imanência e a multiplicidade são sempre escandalosas aos olhos do Um" (ibidem, p. 319).

A ideia de "sociedade-contra-o-Estado" funciona como uma espécie de fórmula que "designa uma forma de vida baseada na despotencialização simbólica e prática da representação coletiva" (ibidem, p. 301). Questionar a representação coletiva é questionar profundamente o nosso modelo social e político, a ideia de que o poder se possui e se delega para receber proteção e segurança. A fórmula expressa também "a inibição estrutural da tendência perene à conversão da autoridade, riqueza e prestígio em coerção, desigualdade e exploração". Essa última característica é realmente difícil de pensar desde uma perspectiva ocidental e "civilizada": para as tribos estudadas por Clastres é possível um chefe que medie sem usar a coerção (sem apoio ou ameaça de uso da própria força, muito menos da força de outros - a polícia, o exército). Clastres salienta que a economia das sociedades sem Estado não se baseia na acumulação (e ainda assim, ou 
precisamente por isso, não implica em miséria alguma nem em desigualdade) $e$ que nelas existe prestígio social não atrelado a nenhum tipo de exploração. Apontaremos aqui que as sociedades ditas primitivas não se compreendem totalmente sem levar em conta o papel que nela tem a guerra, que implica uma "gestão das alianças interlocais guiada pelo imperativo estratégico de autonomia política do grupo local"; voltaremos a esse último ponto, que implica basicamente numa constante atomização (autonomia) e resistência à agregação (que, para Clastres, derivaria em submissão a um poder central).

O longo posfácio que Viveiros de Castro dedica a Arqueologia da violência (2011) está atravessado pela pergunta sobre a vigência do pensamento de Clastres em nossos dias, é por isso que as observações do primeiro muito nos interessam:

E se o Estado existiu desde sempre, como argumentam Deleuze e Guattari (1980: 445), então a sociedade primitiva também existirá para sempre: como exterior imanente do Estado, força de antiprodução sempre a ameaçar as forças produtivas, multiplicidade não interiorizável pelas grandes máquinas mundiais. 'Sociedade primitiva' em suma, é uma das muitas encarnações conceituais da perene tese da esquerda de que um outro mundo é possível: de que há vida fora do capitalismo, como há Sociedade fora do Estado. Sempre houve, e - é para isso que lutamos - continuará havendo (ibidem, p. 304).

Subscrevemos à tese de que as ideias que se concentram em torno da fórmula da sociedade-contra-o-Estado têm ainda muito a dizer ao pensamento contemporâneo, sob a condição de ter sempre presente que a expressão "permanece válida como conceito universal - não como tipo ideal ou como designador rígido de uma espécie sociológica, mas como analisador de toda $e$ qualquer experiência de vida coletiva" (ibidem, p. 318). Tanto as sociedades que Clastres descreve como a teoria que ele propõe nessa descrição rompem, com a força do intempestivo (ibidem, p. 311), a "relação teleológica - melhor dizendo teológica - entre a dimensão política da vida coletiva e a forma-Estado, afirmada $e$ justificada virtualmente por toda a filosofia ocidental" (ibidem, p. 311). Mas não é apenas por isso que Clastres volta e instaura ainda hoje uma ruptura no pensamento: ele representa também o esforço radical - e interminável - de levar a sério o pensamento dos outros. Assunto sempre presente nos dias de hoje e que ainda, precisamente por isso, merece atenção. Parafraseando Clastres: dado que a 
alteridade é de certo modo levada a sério "a questão é saber até onde é levada essa seriedade" (apud ibidem, p. 312).

Acreditamos que uma maneira possível de levar a sério o pensamento consiste em assumir e habitar seus paradoxos. Viveiros de Castro localiza três paradoxos clastrianos:

há um paradoxo da antropologia (o conhecimento não como apropriação mas como despossessão); um paradoxo próprio a cada uma das duas grandes formas sociais (na sociedade primitiva a chefia sem poder; na nossa, a servidão voluntária) e um paradoxo da guerra e do profetismo (dispositivos de indivisão que se tornam os germes de um poder separado) (ibidem, p. 313)

O primeiro paradoxo diz respeito a um problema epistemológico e portanto à questão dos saberes e sua transmissão: contra a ideia de que o saber é progressivo, apropriável e acumulativo, a perspectiva adotada por Clastres exige ao ato de conhecer (note-se que não dissemos ao sujeito de conhecimento) a virtude de se despossuir - ou pelo menos de não parar de tentá-lo - da própria história, dos preconceitos, do lugar central, e também - muito importante - da tentação de tomar os outros "como modelos, fazendo-os passar de 'nossas' vítimas [...] a 'nossos' redentores" (ibidem, p. 314).

A segunda questão paradoxal é a do chefe sem poder - ou sem poder de coerção. Parece praticamente impossível de pensar o que implica em termos de governo de si e relação com os outros pertencer a uma comunidade em que não existe hierarquia política associada a coerção. $\mathrm{O}$ artigo "Liberdade, mal encontro, inominável" (ibidem, 145-62) indaga sobre "esse irracional acontecimento ao qual nós, modernos, chamamos, de [...] nascimento do Estado" (ibidem, p. 148). Clastres não encontra a causa desse acontecimento. Já vimos que na interpretação de Viveiros de Castro essa instituição não tem uma origem histórica, senão que o Estado e a sociedade-contra-o-Estado são dois modelos em conflito de organização e exercício do poder que convivem desde sempre $e^{4}$ Importa aqui mencionar que para Clastres a característica de qualquer sociedade dividida (Estado por um lado, sociedade por outro) é a servidão: a pergunta pela separação entre Estado e sociedade é a pergunta pela renúncia à liberdade. Eis o paradoxo que Clastres

\footnotetext{
4 “ [...] se o Estado existiu desde sempre [...] então a sociedade primitiva também existirá para sempre" (VIVEIROS DE CASTRO, 2011, p. 304).
} 
descreve com a fórmula de La Boétie: servidão voluntária; a servidão voluntária é às sociedades civilizadas o que a chefia sem poder é as sociedades primitivas. Ambas fórmulas paradoxais se referem dois tipos (teóricos) de organização social e exercício do poder diametralmente opostos.

O último paradoxo, o da guerra, diz respeito à unidade e a multiplicidade. Para Viveiros de Castro a guerra não é a interrupção excepcional de um modo vida pacífico que se quer pacífico, mas uma atividade fundamental para o modo de ser das comunidades sem Estado. O sistema de alianças e inimizades das sociedades primitivas, porque ele implica a inconstância $e$ instabilidade da diferenciação entre grupos aliados e inimigos, quebra o paradigma dicotómico entre o nós e os outros (inimigos). Os aliados "formam uma cintura de segurança (e de incerteza) em torno de cada grupo local" (ibidem, p. 347). A figura do aliado é "instável e indispensável" (ibidem, p. 347) para impedir "tanto uma 'reciprocidade generalizada' (a fusão das comunidades em uma unidade sociológica superior) quanto uma guerra generalizada (a atomização suicida do socius)" (ibidem, Loc. cit.). A reciprocidade generalizada significaria $\mathrm{o}$ agrupamento em uma comunidade maior, enquanto a guerra generalizada é o estado que Hobbes, dentre outros, atribuía à sociedade antes do contrato: a luta de todos contra todos ${ }^{5}$. Acontece que a sociedade-contra-o-Estado não se inscreve na polaridade totalidade/atomização, nela

o caráter de totalidade significa que a comunidade não é parte de nenhum outro Todo hierarquicamente superior; o caráter de indivisão significa que ela tampouco está hierarquizada internamente, dividida em partes que formassem um Todo interior. [...] Ausência de distinção localizável entre um dentro e um fora, Multiplicação do múltiplo (ibidem, Loc. cit.)

Não se trata, nas sociedades primitivas, de opor a paz interior à guerra externa, se trata de um constante dissenso e de uma sociedade que nada deve à ideia de bem comum (ibidem, p. 352) e na qual a mobilização guerreira visa "o controle da tentação de controle" (ibidem, p. 302) e está "a serviço da integridade

\footnotetext{
${ }^{5}$ Segundo uma interpretação que Abensour (apud ibidem, p. 302) faz de Clastres " $A$ arqueologia da violência é um Contra-Hobbes". Contra Hobbes porque para Clastres, o estado de guerra de todos contra todos, de existir, nada tem a ver com as sociedades primitivas; assim como o contrato, precisamente por se basear na representatividade) não garante a liberdade, mas consente a servidão.
} 
sociológica" (ibidem, loc. cit.). A sociedade-contra-o-Estado é "uma imagem de nós mesmos onde não nos reconhecemos. Sequer no ideal” (ibidem, p. 352).

Tendo chegado nesse ponto, surge novamente a pergunta: de que nos serve uma imagem onde não nos reconhecemos? Ou, nas palavras de Deleuze e Guattari (apud ibidem, p. 337): "por que voltar aos primitivos, pois que se trata da nossa vida?". A resposta a oferece o próprio Viveiros de Castro: "a mais alta promessa" que a antropologia pode fazer ao pensamento, é a de "nos devolver uma imagem de nós mesmos em que não nos reconheçamos" (MANIGLIER apud ibidem, p. 304). Assim, diz o antropólogo brasileiro, em vez de reduzir as imagens da alteridade, a antropologia cumpre em multiplica-las (ibidem, loc. cit.). Na medida em que toda a força dessas imagens se apodera do nosso pensamento podemos talvez pensar de outro modo ${ }^{6}$. A alteridade é também e essencialmente, uma outra forma de pensamento: o pensamento dos outros e/ou o curto-circuito que faz com que o nosso próprio pensamento se transforme em outro.

Nas sociedades que transformaram a multiplicidade $e$ a diferença em desigualdade - as chamadas civilizadas - as trocas reproduzem essa desigualdade na política e nas relações económicas (BRUNO, 2009, p. 93-4). É para resistir essa reprodução que se faz preciso imaginar outras formas possíveis de trocas.

Clastres nos oferece um outro mundo possível. A impossibilidade de nos reconhecer nesse novo mundo abre vias para pensar as relações entre educação $e$ política, mas, já o apontou Viveiros de Castro, não se trata tomá-los como modelos, mas de permitir que eles abalem o que habitualmente pensamos.

Nas nossas instituições, a troca que aprofunda as desigualdades parece intrínseca. Mas continuamos a atribuir a essas instituições a responsabilidade - ou depositar nelas a esperança - de produzir uma sociedade mais igualitária. Trata-se de funções contraditórias que convivem na nossa lógica e nas nossas práticas. Ter presente essa contradição não implica abandonar os desejos de mudança nem desinvestir as práticas de aprendizado e de ensino. Acreditamos que, pelo

\footnotetext{
${ }^{6}$ Vale a pena lembrar a Zourabichvili "Pensar é sempre pensar de outro modo. Não se pensa senão de outro modo" (2004,p. 46) (Trad. nossa).
} 
contrário, contribui para melhor compreendermos a educação como atividade política.

\section{Michel Foucault: O que queremos saber dos outros? Por que queremos saber dos outros?}

Em As redes do poder $(2005)^{7}$ Michel Foucault afirma que é preciso distinguir a maneira em que nos representamos o poder daquela segundo a qual ele funciona. A grande questão não é o conceito de poder, a representação que dele nos fazemos, nem sequer a pergunta sobre quem detém o poder. Todas essas abordagens se desviam de uma questão central, mais reveladora e urgente: o seu funcionamento.

Segundo Foucault (ibidem, p. 17) foi Clastres o primeiro a se emancipar do primado da proibição $e$ a pensar o poder na sua positividade: ainda que ele seja usualmente representado como limitação ou repressão (ou seja, sob a forma da lei), existem sempre e ao mesmo tempo "mecanismos positivos do poder" (ibidem, p. 19), cuja função não consiste em proibir ou em reprimir, senão em produzir (ibidem, p. 29).

É possível pensar o poder de maneira positiva e plural. O artigo que citamos (2005) toma como referência o livro II de O capital de Marx. Foucault interpreta que ali o poder, ou melhor, os poderes aparecem como "formas de sujeição [heterogêneas] que operam localmente" (2005, p. 19). Na transição histórica do poder medieval - um poder global, macro, com grandes lagunas e "cego" a uma série de intercâmbios, processos e produções que aconteciam na sociedade em níveis não controlados - ao poder monárquico e depois burguês, aparecem novos mecanismos de sujeição. Para Foucault, a modernidade está marcada pelo surgimento de duas formas de poder que agem conjuntamente: individualização e totalização, "de um lado a individualização crescente; de outro lado $e$ simultaneamente, a totalização e a saturação das coerções impostas pelo poder" (VEIGA-NETO, 2003, p. 40).

\footnotetext{
${ }^{7}$ Tradução nossa, como todas as citações do mesmo artigo.
} 
Atômico e individualizante é o poder que se exerce sobre cada indivíduo, mais especificamente sobre seu corpo. Essa forma de está associada a um dispositivo de vigilância que permite ver sem ser visto e ver constantemente, o panóptico. Ele funciona em espaços fechados - instituições de clausura - que são também instituições disciplinares (prisão, hospital, fábrica, asilo, escola, etc.). Mas, junto a um saber que individualiza e disciplina, surge um saber-poder que se aplica às populações e que domina globalmente os dados sobre a vida (biopoder) dos indivíduos permitindo uma nova forma de controle dos sujeitos. Esse saber-poder é exercido sobre grandes grupos de indivíduos computando dados que estes produzem enquanto organismos vivos. Para essa forma de saber-poder global não importa o detalhe, o particular, o indivíduo, mas ele se articula com o saber-poder individualizante e disciplinar:

O descobrimento da população é, ao mesmo tempo que o descobrimento do indivíduo e do corpo adestrável, acredito eu, outro grande núcleo tecnológico em torno do qual os procedimentos políticos do Ocidente se transformaram. (FOUCAULT, 2005, p. 24).

Veiga-Neto (2003) afirma que o biopoder "inventou um novo corpo, a população" (p. 72), objeto que não tinha aparecido para o saber anteriormente: a vida dos indivíduos enquanto aquilo que eles têm de comum e numerável (fecundidade, mortalidade, longevidade, mas também migrações, criminalidade, etc.).

O poder que individualiza é, segundo Foucault (2005), herança de uma forma de poder medieval, eclesiástico, que permitia conduzir o rebanho através de mecanismos que produziam uma quantidade de detalhes sobre cada indivíduo em particular. Essa forma de poder, que o mecanismo da confissão fazia possível, ele a denomina poder pastoral. Herança que veio se juntar ao poder disciplinar permitindo assim "levar o olhar do soberano a toda parte" (VEIGA-NETO, 2003, p. 68) num momento em que a sociedade europeia "se complexificava, crescia e se espalhava pelo mundo afora" (ibidem, loc. cit.). Assim, o Estado moderno não é apenas um poder separado da comunidade, da massa, do povo, etc. Ele se expande numa rede de vigilâncias, exames, classificações, sequências, distribuições etc., graças aos quais se organizam os corpos e se corrigem as almas - que são 
produzidas através do corpo e se tornam, por sua vez, instrumento para governo daquele. Ao utilizar o termo alma, que remete a uma longa tradição filosófica $e$ metafísica, Foucault parece estar ironizando sobre uma possível separação idealista de corpo e alma e afirmando, na verdade, que é modulando o corpo que se cria a alma, que é através do corpo e do tratamento que esse recebe que o sujeito se fabrica. Os poderes exercidos sobre os corpos não apenas reprimem, eles produzem sujeitos com determinadas características: eles sujeitam. Hábitos e mecanismos organizam e ajustam o corpo a determinadas tarefas e organizações do tempo e do espaço, introduzem assim na alma a competência de se autogovernar, isto é, a capacidade de se ajustar e reajustar a formas historicamente determinadas de ser e de querer:

Cada um vê a disciplinaridade do e sobre o próprio corpo não apenas como algo necessário, mas como [ ... ] natural. [...] a disciplina funciona também como uma matriz de fundo [...]. Mesmo que não sejamos todos igualmente disciplinados, todos compreendemos - ou devemos compreender... - o que é ser e como se deve ser disciplinado (ibidem, p. 71).

Um conceito articula saber-poder individualizante e saber-poder totalizante: o de normalidade. Para Foucault o poder, a partir de um determinado momento, responde mais à forma da norma (à ideia de normalidade) que à forma da lei (lembremos a advertência de não pensar o poder juridicamente). A partir da ideia de normalidade a política (biopolítica, já que intervém nos ciclos vitais) prevê desvios e os regulamenta, "articula os mecanismos disciplinares (que atuam sobre o corpo) com os mecanismos regulamentadores (que atuam sobre a população)" (ibidem, p. 74). A norma individualiza (os desvios) e remete sempre ao conjunto normalizado. Ela compara indivíduos entre si e com o grupo, classificando de anormal "aqueles cuja diferença em relação à maioria se convencionou ser excessiva, insuportável" (ibidem, p. 75). A norma é a régua de um mecanismo traduz a alteridade em desvio, a diferença em anormalidade.

Foucault ensina que o poder funciona em redes e não apenas de "cima para baixo". Não é mais possível, depois de Foucault, pensar o poder de "forma esquemática, como: de um lado estão os que têm o poder e do outro os que não o têm" (FOUCAULT, 2005, p. 30). Se Clastres nos mostrou que certos dispositivos 
de poder podem ser neutralizados por regras específicas que visam a evitar a aparição do Estado, Foucault realiza uma minuciosa análise do poder estatal e traça sua genealogia, descrevendo formas diversas de funcionamento que agem ao interior da máquina estatal e a fazem possível, revelando que o Estado não é apenas a uma instância separada que se reserva o poder de coerção, senão que depende de mecanismos de poder que se estendem em rede e se alimentam entre si. O exercício do poder se complexifica e se pluraliza, eventualmente todos exercemos o poder estatal ou uma indispensável porção desse, médicos, professores, psicólogos e psiquiatras, estatísticos, mães, maridos, etc.

Até aqui uma apresentação mais teórica de alguns pontos importantes da concepção foucaultiana de poder, vale a pena apresentar também algumas ideias mais concretas sugeridas pelo próprio autor sobre isso que ele denomina o seu funcionamento. Como identificar os mecanismos desse poder que se ramifica através da sociedade toda? Para onde dirigir o olhar se queremos observar o poder no seu funcionamento? O artigo "O sujeito e o poder" (FOUCAULT, 1995) fornece algumas pistas. Em primeiro lugar, como já dissemos, não se trata do poder em singular, mas de diferentes formas de poder, Foucault propõe detectar e analisar racionalidades específicas, havida conta da relação entre poder totalitário e racionalidade que fora denunciada por várias correntes do pensamento político, em particular depois da primeira guerra mundial.

Para detectar isso que Foucault chama de funcionamento do poder, ele mesmo recomenda "usar as formas de resistência contra as diferentes formas de poder como um ponto de partida" (1995, p. 234, trad. nossa, grifo nosso). Alguns exemplos que ele mesmo oferece: a resistência das mulheres ao poder dos homens, dos filhos ao poder dos pais, dos pacientes ao poder da medicina, etc. Podemos também citar aqui, já que o assunto é de nosso interesse, os questionamentos que a educação como projeto nacional recebe por parte de movimentos libertários e as muitas formas de resistência a essa instituição que tem surgido, em particular no século XX. Também a resistência não formal, não organizada e constante que os alunos opõem a ela. 
Não basta, ensina Foucault, com detectar esses movimentos de resistência e dizer que eles são "lutas antiautoritárias", é possível "definir mais precisamente o que elas têm em comum". Eis algumas características (1995, p. 234-5):

1- São transversais, transcendem as fronteiras dos países, não se limitam a um deles;

2- têm como objetivo os efeitos do poder em si, independentemente de que esses efeitos gerem também exploração e proveito econômico (não porque este último seja irrelevante, mas porque para Foucault a exploração econômica não se entende sem a dominação social e sem a forma de dominação que ele denomina sujeição);

3- são lutas contra o inimigo imediato e não contra um inimigo principal: questionam as instâncias de poder que lhe são mais próximas, as práticas médicas ou psiquiátricas, o poder policial, etc. e focam nas técnicas de poder e não nas instituições em si;

4- questionam o status do indivíduo ao afirmarem a diferença ao mesmo tempo em que questionam tudo o que enfraquece a vida comunitária. São lutas contra a individualização como forma de poder e contra as "soluções" isoladas ou individualistas;

5- são também lutas contra os privilégios do saber, das competências e da qualificação. Não se trata de uma crítica ao saber em si, mas à maneira pela qual o saber circula, funciona, entra em relação com o poder;

6- resistem a violência "econômica e ideológica" que ignora quem somos individualmente, mas também contra a "investigação científica ou administrativa que determina quem somos";

Insistimos, essas formas de resistência que Foucault descreve não têm como objeto uma instituição, mas sim uma técnica de poder, em particular aquela que "marca" o indivíduo amarrando-o a uma identidade (sujeição). Daí a célebre denúncia foucaultiana: o sujeito, que, para a filosofia moderna, era fundamento do conhecimento e da ação, é também - e aparentemente sempre - sujeitado pelos saberes e práticas da sua época. O lugar que era antigamente ocupado pela ideia de salvação, passa - na época em que ele escreve e, acreditamos, na nossa - a ser 
ocupado pela busca de garantias de segurança, saúde, bem-estar, etc. Isso justifica um "reforço da administração": polícia, família, saber médico, hospitais, etc., transformam-se em agentes dessa administração (as instituições educativas se contam também entre esses agentes).

A conclusão de Foucault é, no mínimo, inquietante: seria desejável "nos liberarmos tanto do Estado quanto do tipo de individualização que a ele se liga. Temos que promover novas formas de subjetividade através da recusa deste tipo de individualidade que nos foi imposto há vários séculos" (ibidem, p. 239). Formas de individuação baseadas na diferença e não na identidade, que se recusem a dizer ao outro quem ele é e façam possível, inclusive, uma espécie de direito à inconstância.

Se no item anterior questionamos a naturalização do Estado como forma única de exercício do poder, expomos aqui uma noção de poder que permite detectar mecanismos plurais agindo ao mesmo tempo e de maneiras diversas capilarizando o corpo social, em lugar de emanar apenas de um poder central. Apresentamos uma forma de poder não soberana e separada, mas uma complexificação dessa concepção que propõe a multiplicação das formas de exercício do poder. Assim, podemos pensar agora num poder que não consista apenas em dominar, explorar ou mandar. A série das operações associadas ao exercício do poder cresce: separar, hierarquizar, disciplinar, vigiar, examinar, normalizar, classificar, etc. Todas elas presentes no campo da Educação e/ou na sua história.

\section{Jacques Rancière: Quem quer uma explicação? O que querem as explicações?}

O mestre ignorante de Jacques Rancière (publicado na França no final dos anos 80 e no Brasil em 2003) detecta uma lógica própria das instituições escolares modernas, a "lógica da explicação", cuja função vai muito além de explicar: ela divide a sociedade entre os explicadores e aqueles que precisam de explicação, ao mesmo tempo em que fornece a essa sociedade um modelo e uma justificativa 
para a classificação hierárquica dos indivíduos (já não apenas dos estudantes, mas dos cidadãos em geral).

Para melhor apresentar $O$ mestre ignorante é preciso retomar a história que o livro conta. Começa em 1818, quando um professor francês chamado Joseph Jacotot, obrigado a deixar a França por razões políticas, é convidado para dar aulas nos Países Baixos. Uma vez ali, encontra-se com uma limitação que à maioria dos mortais pareceria intransponível: seus alunos não falam francês, ele não fala flamenco. Com ajuda da edição bilíngue - flamenco/francês - de um livro (Telémaco de Fénelon) e um intérprete cuja função se limita a pedir aos alunos que aprendam sozinhos a língua francesa utilizando esse libro, Jacotot realiza uma experiência pedagógica (e política) bastante revolucionária. Surpreendentemente, seguindo sua iniciativa, os alunos conseguem aprender francês. A cada fase do aprendizado, Jacotot pergunta apenas o que eles têm aprendido e confere que façam seu trabalho com atenção. Os alunos aprendem por si. Essa breve história pedagógica, essa "aventura intelectual", como a denomina Rancière, confirma uma suspeita que muitos já tiveram: que é possível adquirir conhecimento sem ajuda da instituição educativa, e mais do que isso, que aprender sem a mediação de um explicador é política e pedagogicamente falando, a melhor forma de aprender.

Jacques Rancière destaca um ponto na estratégia de Jacotot: o fato dela colocar em questão o método educativo por excelência - a explicação - e suas consequências em termos políticos. Com efeito, a grande maioria dos professores e dos alunos fomos levados a acreditar e continuamos no fundo acreditando que ensinar consiste em explicar, mas Jacotot lança seu desafio que uns 170 anos depois Rancière acolhe e desenvolve: não só é possível ensinar sem explicar, é possível também ensinar o que se ignora. Não satisfeito em aplicar seu "método" apenas ao ensino do francês, Jacotot, conta Rancière, tenta ensinar outras disciplinas sobre as quais nada sabe: pintura, piano, etc. Os alunos lotam suas aulas e nelas aprendem seguindo seus próprios caminhos enquanto o mestre só pergunta uma e outra vez: "o que vês?"; "o que pensas disso?"; "o que fazes com 
isso?" Não verifica o conteúdo do que o aluno encontra, mas interroga sobre a busca, o processo, a transição. E anima o aluno a não cessar nela.

A história de Jacotot, pelo menos como Rancière a $\operatorname{trata}^{8}$, é a história de uma ruptura. Afirmar que ensino e explicação não estão ligados necessariamente é por em questão o papel dos intermediários da formação, os funcionários explicadores. O que aparentemente mais interessa a Rancière é inscrever no campo político as consequências dessa ruptura pedagógica: "assim vai a crença na desigualdade. Não há espírito superior que não encontre um mais superior ainda, para rebaixá-lo; não há espírito inferior que não encontre outro mais inferior ainda, para desprezar" (2002, p.51). Rancière questiona a divisão entre explicadores e explicados porque ela confirma e produz uma hierarquia que atravessa a sociedade toda. É por isso que ele descreve a nossa como uma "sociedade pedagogizada", onde as hierarquias se naturalizam da mesma forma que na escola, afirmando que alguém não é ainda todo o que pode chegar a ser, mas que pode e deve continuar a se esforçar, isto é, que a igualdade pode ser alcançada em algum ponto, se nos submetemos às devidas explicações. É assim que todos parecemos querer uma explicação, exigir uma explicação. Acreditamos nas explicações, as desejamos e a prescrevemos aos outros. $\mathrm{O}$ caminho da igualdade nutre a hierarquia.

Contra a sociedade pensada como uma grande escola, Rancière empunha a arma de Jacotot: afirmar - de fato - a igualdade das inteligências. No começo. Como uma espécie de a priori ético e político. Há um problema que, segundo Rancière, nem os progressistas nem seus detratores parecem enxergar: a igualdade não pode ser um fim, ou bem ela é confirmada desde o começo, ou ela funciona como uma igualdade fantasma, como promessa de uma igualdade futura, isto é, ocultando e negando as desigualdades presentes:

Não mais proletários, apenas recém-chegados que ainda não entraram no ritmo da modernidade, ou atrasados que, ao contrário, não souberam se adaptar às acelerações desse ritmo. A sociedade se representa, assim,

\footnotetext{
${ }^{8}$ Como bem aponta Walter Kohan (2011, p. 98), em O mestre ignorante não é possível - nem parece importante - distinguir até onde vai a voz de Jacotot e onde começa a interpretação de Rancière. É de Kohan que copiamos a fórmula Rancière/Jacotot que expressa essa indefinição.
} 
como uma vasta escola que tem seus selvagens a civilizar e seus alunos em dificuldades a recuperar. (RANCIÈRE, 2002, p. 13)

O outro não é mais simplesmente selvagem nem não humano, ele pode aprender, é sujeito educável. O mecanismo escolar se difunde na sociedade, ninguém é isento, todos ocupamos um lugar não em uma, mas em várias hierarquias. Ora, a hierarquização não é uma operação de sujeição qualquer, como nos lembra Christian Ferrer (2005):

Para Bakunin, as modalidades da dominação se adaptavam às grandes mudanças históricas, mas as significações imaginárias associadas com a hierarquia persistiam e se constituíam em interdito, em condição de impossibilidade para pensar o segredo do domínio. Ao longo do século de XX, tem circulado no espaço público a questão da "dignidade" econômica e foi possível "tratar" a opressão de "gênero": estes já adquiriram alguma sorte de carta de cidadania enquanto problemas teóricos, políticos, gremiais, académicos ou jornalísticos. Porém, a hierarquia permanece um tabu (Ibidem, p. 11, trad. nossa).

A hierarquia permanece um tabu. Para Rancière, a escola funciona como um modelo (de hierarquização, de justificação da meritocracia) segundo o qual a sociedade se representa a si mesma, "escola e sociedade infinitamente se simbolizam uma à outra" (2002, p. 13). Contra o tabu da hierarquização, ele apenas conta uma história. É importante que ele não construa uma teoria, nem se proponha a resolver um problema, mas apenas aponte um momento singular em que o acaso intervém e desvela uma possibilidade, a da igualdade como ponto de partida.

"Jacotot se aventura pelo caminho da emancipação intelectual, mas só quando ao mesmo tempo renuncia ao lugar de professor, isto é, quando deixa vazio o lugar da eloquência de quem sabe o que diz e diz o que fazer" (YUING, 2014, p. 203, trad. nossa). Detectar a nossa própria posição hierárquica, renunciar àquilo que estabelece uma necessária correspondência entre o que somos e o lugar que ocupamos, a cada vez, porque este "método", apesar de seu nome, nos convida a cultivar a singularidade.

Para Rancière/Jacotot a igualdade é paradoxal, "fundamental e ausente", fundamental porque se não é colocada de antemão, ele se transforma em uma armadilha, ausente porque de fato, vivemos numa sociedade pedagogizada, 
hierarquizada, onde apenas de maneira singular e muitas vezes imprevisível pode se abrir um espaço em que a hierarquia seja suspensa. A igualdade;

não consiste nem no ensino uniforme de crianças da república, nem na
disponibilidade dos produtos de baixo preço nas estantes de
supermercado [...] ela é atual e intempestiva, sempre dependendo da
iniciativa de indivíduos e grupos que, contra o curso natural das coisas,
assumem o risco de verificá-la, de inventar as formas, individuais ou
coletivas, de sua verificação. (RANCIĖRE, 2002, p. 14)

A tensão entre Educação e igualdade não pode ser anulada, permanecemos nela. Afirmar a igualdade como ponto de partida não é sempre possível. Mas há oportunidades de verificar essa igualdade, de aproveitar as falhas do paradigma da igualdade-promessa. Afinar nossa percepção para não deixar escapar essas oportunidades, renunciar à função intermediária de funcionário da explicação, deixar vazio, mesmo que transitoriamente o lugar hierárquico que nos é destinado, questionar nossa própria necessidade de explicação, são iniciativas possíveis contra esse "curso natural das coisas".

\section{Notas finais}

Este trabalho não visa uma crítica destrutiva da escola ou da educação como instituição. Seu propósito é o contrário disso. Ao colocar em questão diferentes aspectos das nossas instituições políticas, dentre elas a educação, adere a uma forma de pensar a política e de agir politicamente que não lida com grandes conceitos, que não dita o que fazer, que não espera uma revolução definitiva, mas deposita suas esperanças nas pequenas práticas cotidianas como oportunidades de resistência.

Assim, Clastres nos ensina a desconfiar de nós mesmo como conhecedores dos outros, a questionar até que ponto nesse - constante - falar dos outros, os estamos levando a sério. Ele nos ensina sobretudo a construir um saber sobre os outros que, em lugar de estabelecer o que "Ihes falta", seja capaz de abalar o nosso mundo, de desconstruir o que sabemos ou acreditamos saber sobre nós, de interromper a tranquila certeza de que nossa ordem política faz mais sentido do que outras. 
Nem é sempre evidente que tanto saber o que os outros precisam saber quanto saber determinadas coisas sobre os outros (os pacientes, os criminosos, os alunos) consiste em exercer um poder. Foucault detecta os mecanismos que permitem esse exercício não para estabelecer um método, um plano ou uma teoria capazes de erradicar de uma vez a sujeição que provocam. O filósofo se cuida de cair nas macelas da solução mais ou menos definitiva. A sua estratégia é mostrar a fragilidade daquilo que consideramos inamovível - nossos pressupostos históricos , assim como desvendar uma multiplicidade que não enxergávamos, para talvez propiciar as formas de resistência. Acreditamos que seja essa uma das virtudes que fazem dele um autor praticamente ineludível no campo da Educação.

Rancière nos questiona sobre a necessidade da explicação e, em sentido amplo, sobre os mecanismos que perpetuam as hierarquias sociais que bem conhecemos. Ele insinua que na mesma escola onde se reproduz a desigualdade pode se revolucionar uma certa ordem.

Outorgamos aqui certo destaque aos paradoxos que os nossos autores revelam e exploram: conhecimento como despossessão, servidão voluntária, chefia sem poder, igualdade fundamental e ausente, etc. Esperamos que esses paradoxos por si fiquem ressoando e assim extravasem, questionem e finalmente arruínem todas as explicações aqui contidas.

\section{REFERÊNCIAS}

ADORNO, Theodor; HORKHEIMER, MAX W. A dialética do esclarecimento. Tradução de Guido Antônio de Almeida. Rio de Janeiro: Jorge Zahar, 1985.

BENJAMIN, Walter. "Sobre o conceito de História". In: Obras Escolhidas. Magia e Técnica, Arte e Política. $7^{\mathrm{a}}$ ed. Brasiliense: São Paulo, 1994.

BRUNO, Lúcia Emília Nuevo Barreto. "Poder político e sociedade: qual sujeito, qual objeto?”. In: BARTOLOZZI FERREIRA, Eliza; OLIVEIRA, Dalila Andrade. Crise da escola e políticas educativas. Belo Horizonte: Autêntica, 2009, p. 81-120.

CLASTRES, Pierre. A sociedade contra o Estado. Trad. Theo Santiago. 1a. reimpressão. São Paulo: Cosac Naify, 2013. 
CLASTRES, Pierre. Arqueologia da violência. Trad. Paulo Neves. Prefácio Bento Prado Jr. Posfácio Eduardo Viveiros de Castro. 2. ed. São Paulo: Cosac Naify, 2011.

DELEUZE, Gilles; GUATTARI, Félix. Mille Plateaux - Capitalisme et Squizophrénie II. Paris: Minuit, 1980.

FERRER, Christian. "Sobre los libertários". In FERRER, Christian (Compilador). El lenguaje libertario: antología del pensamiento anarquista contemporáneo. La Plata: Terramar, 2005.

FOUCAULT, Michel. Las redes del poder. In: FERRER, Christian (Compilador). EI lenguaje libertario: antología del pensamiento anarquista contemporáneo. La Plata: Terramar, 2005.

FOUCAULT, Michel. O sujeito e o poder. In: RAVINOW, P.; DREYFUS, H. Michel Foucault. uma trajetória filosófica (para além do estruturalismo e a hermenêutica). Rio de Janeiro: Forense Universitária, 1995.

RANCIÈRE, Jacques. "La difícil herencia de Michel Foucault". Paralaje. Revista de Filosofía, no 11, 2014.

RANCIÈRE, Jacques. $O$ mestre ignorante: cinco lições sobre a emancipação intelectual. Trad. Lílian do Vale. Belo Horizonte: Autêntica, 2002.

SILVA, Franklin Leopoldo e. "Conhecimento e Razão Instrumental". Psicol. USP, São Paulo,v. 8, n. 1, 1997. Disponível em $<$ http://www.scielo.br/scielo.php?script $=$ sci arttext\&pid $=$ S0103-

$65641997000100002 \& \operatorname{lng}=e n \& n r m=$ iso $>$. Acesso em 28 fev. 2015.

VEIGA-NETO, Alfredo. Foucault e a educação. 2. ed. Belo Horizonte: Autêntica, 2005.

VIVEIROS DE CASTRO, Eduardo. Posfácio. In CLASTRES, Pierre. Arqueologia da violência. 2. ed. São Paulo: Cosac Naify, 2011.

YUING, Tuillang. "Nota preliminar del traductor". In RANCIÈRE, Jacques. "La difícil herencia de Michel Foucault". Paralaje. Revista de Filosofía, no 11, 2014.

ZOURAVICHBILI, François. Deleuze, una filosofía del acontecimiento. Trad. Irene Agoff. Buenos Aires: Amorrortu, 2004. 